Goñi, M.J. Federalismo fiscal. Importancia de la autonomía municipal para el desarrollo sostenible. Derecho y Ciencias Sociales. Abril 2017. № 16 (Temas relativos al desarrollo regional y local) Pgs 22- 39. ISNN 1852-2971. Instituto de Cultura Jurídica y Maestría en Sociología Jurídica. FCJ y S. UNLP.

\title{
Federalismo fiscal. Importancia de la autonomía municipal para el desarrollo sostenible.
}

Fiscal Federalism. Importance of municipal autonomy for sustainable development.

María J. Goñi•

\section{Resumen.}

En el presente trabajo, se entiende que para alcanzar el desarrollo sostenible es necesario consagrar una verdadera autonomía municipal y que la autonomía económico financiera supone que el municipio pueda procurarse sus propios recursos sin intervención de ningún otro orden estatal sin perjuicio de que perciben recursos provenientes de regímenes de coparticipación. El derecho público provincial, ha dado sustento a la posibilidad de generar el financiamiento necesario para el crecimiento de los sistemas tributarios y de administración tributaria de las municipalidades, en este sentido, diversas constituciones provinciales, han consagrado para sus municipios la facultad de que puedan percibir verdaderos impuestos considerando las tensiones que surgen en la práctica de nuestro federalismo, que se ha tornado cada vez más unitario.

Palabras Clave: Federalismo, municipalidades, autonomía, desarrollo sustentable.

\begin{abstract}
.
In the present work, it is understood that in order to achieve sustainable development, it is necessary to consecrate a true municipal autonomy and that financial economic autonomy means that the municipality can procure its own resources without intervention of any other state order without prejudice to the fact that they receive resources from Co-participation schemes. Provincial public law, has given support to the possibility of generating the necessary financing for the growth of the tax systems and tax administration of the municipalities. In this sense, various provincial constitutions, have consecrated for their municipalities the faculty that they can perceive real taxes considering the tensions that arise in the practice of our federalism, which has become more and more unitary.
\end{abstract}

Key word: Federalism, municipalities, autonomy, sustainable development.

\footnotetext{
- María Josefina Goñi es integrante del equipo de investigación y docente de la Cátedra I de Derecho Público Provincial y Municipal, de la Facultad de Ciencias Jurídicas y Sociales de la Universidad Nacional de La Plata. mariajosefinagoni @ gmail.com. El presente trabajo, es parte del proyecto de Investigación 11/ J 157. "Desarrollo sustentable", realizado en la Facultad de Ciencias Jurídicas y Sociales de la Universidad Nacional de La Plata.
} 
Goñi, M.J. Federalismo fiscal. Importancia de la autonomía municipal para el desarrollo sostenible. Derecho y Ciencias Sociales. Abril 2017. № 16 (Temas relativos al desarrollo regional y local) Pgs 22- 39. ISNN 1852-2971. Instituto de Cultura Jurídica y Maestría en Sociología Jurídica. FCJ y S. UNLP.

\title{
Federalismo fiscal. Importancia de la autonomía municipal para el desarrollo sostenible.
}

\author{
María J. Goñi
}

\section{Introducción.}

En actualidad el municipio es el núcleo de cualquier estrategia de desarrollo humano. En el marco del desarrollo sostenible, se reivindica la importancia de los gobiernos locales. La descentralización fiscal requiere la autonomía de los gobiernos municipales. Debido a que los municipios se enfrentan al cumplimiento de numerosas funciones que implican el aumento de sus responsabilidades, hoy no se los puede reducir a la dimensión ser meros prestadores de servicios.

Al régimen Municipal consagrado constitucionalmente, se lo enfoca desde la autonomía, que comprende la posibilidad de ejercer el poder tributario, resultado necesario en este marco apuntalar la consagración de la autonomía institucional, política, administrativa, económicafinanciera y participativa y confirmar la necesaria competencia del municipio para fortalecer nuestra democracia, como el ámbito más legítimo y favorable para el desarrollo de la vida política.

\section{Desarrollo sostenible.}

De acuerdo con Heredia, 2005: 246, se entiende al desarrollo como “...el incremento sostenido de la producción de bienes y servicios en un territorio determinado, que tiene por efecto un aumento del bienestar de sus habitantes, en un ambiente de refuerzo de las identidades y la cultura, de ampliación de la democracia, de respeto a los derechos humanos y de equidad de género" " El desarrollo supone la acción política del Estado y la promoción de una institucionalidad democrática y descentralizada que estimule al máximo las iniciativas y acciones locales. El desarrollo debe descansar en el funcionamiento de gobiernos locales autónomos, fuertes y democráticos que posibiliten la participación permanente de los ciudadanos. Son las instituciones locales las que permiten la distribución equitativa de los frutos del desarrollo, y los gobiernos subnacionales los que deben crear y sostener climas de confianza, convivencia y estabilidad para posibilitar un desarrollo local humano y sustentable.

\footnotetext{
${ }^{1}$ La concepción de desarrollo es la sustentada por IULA- Agenda del Municipio Latinoamericano, Propuesta para la discusión. Hacia una agenda municipal Latinoamericana. Visión y misión de los gobiernos locales, Borrador para la discusión, Federación Latinoamericana de Ciudades, Municipios y Asociaciones (FLACMA), documento para su consideración en Asamblea durante el I Congreso de Municipalidades de America Latina México 2002.
} 
Goñi, M.J. Federalismo fiscal. Importancia de la autonomía municipal para el desarrollo sostenible. Derecho y Ciencias Sociales. Abril 2017. № 16 (Temas relativos al desarrollo regional y local) Pgs 22- 39. ISNN 1852-2971. Instituto de Cultura Jurídica y Maestría en Sociología Jurídica. FCJ y S. UNLP.

La descentralización consiste en la devolución de poder, es decir la transferencia de competencias y recursos del gobierno central a los gobiernos locales, en un marco de autonomía. La asignación de competencias debe atender el principio de subsidiariedad que establece que son los gobiernos locales los que tienen primacía para asumir las funciones públicas del desarrollo por su proximidad a la comunidad.

La literatura, la internacional y la Argentina, destaca la importancia de fortalecer a los municipios para adaptarlos a las nuevas demandas y para que asuman el rol de impulsores del desarrollo local. Los caminos que llevan a esa conclusión son, por un lado, la proximidad de la ciudadanía, que posibilita que la provisión de servicios se adapte a la demanda local y que existan mecanismos de control ciudadano. En el presente el sector municipal enfrenta demandas crecientes de sus servicios, sus sistemas tributarios y de administración tributaria no están trazados para generar el financiamiento necesario para ese crecimiento, las municipalidades son "Transferencia dependientes" lo que, les limita la autonomía y posibilita comportamientos fiscalmente irresponsables.

\section{1. Aspectos generales del federalismo, con particular atención al federalismo fiscal.}

El federalismo consiste en la descentralización política del poder con relación al territorio que se caracteriza por la autonomía de sus estados miembros. La reforma a la Constitución Nacional, del año 1994 incorpora las autonomías de la Ciudad de Buenos Aires y de los municipios. En la actualidad la Argentina cuenta con cuatro niveles de gobierno, el gobierno federal, los gobiernos de provincia, el Gobierno Autónomo de la Ciudad de Buenos Aires; y los gobiernos municipales autónomos, reconocidos en los artículos 5 y 123 de la CN. El sistema de distribución de competencias entre la nación y las provincias ${ }^{2}$, no fue modificado por la reforma constitucional de 1994, dejando vigente la regla de las competencias reservadas, consagrada en el anterior artículo 104, actual 121, dicha cláusula de reparto de competencias ${ }^{3}$

\footnotetext{
${ }^{2}$ El federalismo, como forma de Estado, consiste en la división del poder con relación al territorio, muestra una diversidad territorial, en la cual, las competencias se distribuyen entre el Estado central y los Estados miembros. En un mismo territorio se presentan diferentes órdenes de gobierno, en el cual debe sostenerse la unión en la diversidad. Las provincias se encuentran insertas en el Estado nacional son autónomas, tienen poderes propios que han conservado, poderes concurrentes y poderes prohibidos. La autonomía provincial, no significa subordinación al gobierno federal, salvo cuando por mandato constitucional el gobierno federal representa el interés general de la Nación, consagrado en los artículos $5^{\circ}, 6^{\circ}$ y 31 .

${ }^{3}$ La Distribución de competencias en nuestro Estado federal, surge de la Constitución Nacional que en el Art. 121 establece la cláusula de reparto de las mismas al decir que "Las provincias conservan todo el poder no delegado por esta Constitución al gobierno federal..." En el deslinde de competencias en nuestro Estado federal, la nación y las provincias, son independientes entre sí, porque las provincias han conservado los poderes que ya tenían por el Pacto Federal y otros por la delegación que hicieron, en la Constitución de 1853. 60. Nuestro
} 
Goñi, M.J. Federalismo fiscal. Importancia de la autonomía municipal para el desarrollo sostenible. Derecho y Ciencias Sociales. Abril 2017. № 16 (Temas relativos al desarrollo regional y local) Pgs 22- 39. ISNN 1852-2971. Instituto de Cultura Jurídica y Maestría en Sociología Jurídica. FCJ y S. UNLP.

fue afectada por el proceso de centralización que sufrió el país, resultando los avances de gobierno federal sobre los gobiernos provinciales avalados por la Jurisprudencia de la Corte Suprema.

Nuestro federalismo fiscal, se ha hecho cada vez más unitario, alejado del federalismo conciliador concebido en la Constitución de 1853-60. En los últimos tiempos las provincias se han visto postergadas en su participación nacional, en el marco de un federalismo relegado por prácticas políticas del Poder Ejecutivo nacional, y encontrando a los gobernadores subordinados a la autoridad del Presidente de la República.

A pesar de la consagración constitucional de la Coparticipacion federal de impuestos ${ }^{4}$, la ley que permanece vigente ${ }^{5}$, es la que fuera sancionada con carácter transitorio, y permanece con

federalismo encuentra a la Nación y a las provincias como esferas de gobierno, las subordinadas a la Constitución Nacional que es suprema para todos, y que contiene en su parte orgánica la distribución de competencias, a partir del principio consagrado en el artículo 121. Con respecto al reparto de competencias consagradas en la Constitución Nacional, encontramos: facultades delegadas por las provincias al Estado federal, concurrentes de las provincias con el Estado federal y prohibidas al Estado federal o a los Estados provinciales.

4 De acuerdo con Ziulu, 1997: 334, la Coparticipacion es un "Régimen de colaboración acordado entre el Estado Federal y las provincias en virtud de leyes convenio por medio de las cuales las provincias delegan en el poder central el ejercicio de determinadas facultades impositivas con la condición de participar en un sistema de reparto de los impuestos incluidos en ese régimen." 4

La constitución nacional, en el inciso $2^{\circ}$ del artículo 75, consagra la Coparticipación federal de impuestos, como sistema de coordinación financiera, establece que los impuestos indirectos internos y los directos por tiempo determinado son coparticipables. En nuestro Estado federal, el sistema de Coparticipacion presenta la conformación de una masa coparticipable, una distribución primaria y una distribución secundaria. La Coparticipacion primaria es la masa de recursos impositivos que la Nación reconoce a las provincias y a la Ciudad de Autónoma de Buenos Aires y cuanto retiene para si. La Coparticipacion secundaria, consiste en la redistribución de la parte que les corresponde a las provincias y a la Ciudad Autónoma de Buenos Aires entre si, según determinados criterios, mecanismos o porcentajes. El inciso 2 del artículo 75, recepta la Coparticipacion federal de impuestos, y su correspondiente ley reglamentaria aun no se ha establecido, a pesar del mandato constitucional que surge de la disposición transitoria sexta de la constitución reformada en el año 1994.

"Art. 75.- Corresponde al Congreso: ...

2. Imponer contribuciones indirectas como facultad concurrente con las provincias. Imponer contribuciones directas, por tiempo determinado, proporcionalmente iguales en todo el territorio de la Nación, siempre que la defensa, seguridad común y bien general del Estado lo exijan. Las contribuciones previstas en este inciso, con excepción de la parte o el total de las que tengan asignación específica, son coparticipables.

Una ley convenio, sobre la base de acuerdos entre la Nación y las provincias, instituirá regímenes de coparticipación de estas contribuciones, garantizando la automaticidad en la remisión de los fondos

La distribución entre la Nación, las provincias y la ciudad de Buenos Aires y entre éstas, se efectuará en relación directa a las competencias, servicios y funciones de cada una de ellas contemplando criterios objetivos de reparto; será equitativa, solidaria y dará prioridad al logro de un grado equivalente de desarrollo, calidad de vida e igualdad de oportunidades en todo el territorio nacional.

La ley convenio tendrá como Cámara de origen el Senado y deberá ser sancionada con la mayoría absoluta de la totalidad de los miembros de cada Cámara, no podrá ser modificada unilateralmente ni reglamentada y será aprobada por las provincias.

No habrá transferencia de competencias, servicios o funciones sin la respectiva reasignación de recursos, aprobada por ley del Congreso cuando correspondiere y por la provincia interesada o la ciudad de Buenos Aires en su caso. Un organismo fiscal federal tendrá a su cargo el control y fiscalización de la ejecución de lo establecido en este inciso, según lo determine la ley, la que deberá asegurar la representación de todas las provincias y la ciudad de Buenos Aires en su composición.

3. Establecer y modificar asignaciones específicas de recursos coparticipables, por tiempo determinado, por ley especial aprobada por la mayoría absoluta de la totalidad de los miembros de cada cámara."

A pesar del mandato constitucional, la ley vigente sigue siendo la 23. 548 de 1988. La Constitución Nacional 
Goñi, M.J. Federalismo fiscal. Importancia de la autonomía municipal para el desarrollo sostenible. Derecho y Ciencias Sociales. Abril 2017. No 16 (Temas relativos al desarrollo regional y local) Pgs 22- 39. ISNN 1852-2971. Instituto de Cultura Jurídica y Maestría en Sociología Jurídica. FCJ y S. UNLP.

modificaciones que surgieron de la concertación del Poder Ejecutivo Nacional y de los gobernadores provinciales, interviniendo el Poder Legislativo posteriormente en su ratificación, dejando de lado la relevancia institucional del Congreso Nacional y de las Legislaturas provinciales.

En nuestro país, en los últimos años aumentaron las transferencias inter jurisdiccionales, debido al desbalance que se produjo entre responsabilidades de gasto, con motivo del proceso de descentralización de gastos y la centralización de recursos. En la actualidad, la distribución de recursos coparticipables a las provincias es irrazonable, y repercute en las transferencias de recursos hacia los municipios, dificultándoles el cumplimiento de sus atribuciones. En nuestro Estado federal las potestades tributarias de las provincias y de los municipios, se encuentran recortadas ya que además de las normas fiscales propias del derecho público local, se ha desarrollado un entramado legal o derecho intra federal representado por leyes, pactos y convenios inter jurisdiccionales, ratificados por los correspondientes poderes legislativos que enmarcan y limitan la posibilidad de gastar de cada fisco ${ }^{6}$. El sistema de Coparticipacion en la

reformada en el año 1994 en la disposición transitoria Sexta prevé que "Un régimen de coparticipación conforme a lo dispuesto en el inc. 2 del Art. 75 y la reglamentación del organismo fiscal federal, serán establecidos antes de la finalización del año 1996... “"

${ }^{5}$ Ley de coparticipación federal de recursos fiscales. $\mathrm{N}^{\mathrm{o}} 23.548$, constituye un ejemplo de coordinación tributaria vertical, se trata de una "ley convenio" que requiere la sanción por parte del Honorable Congreso de la Nación y la posterior adhesión de las legislaturas provinciales por leyes locales. La Corte Suprema, se ha pronunciado argumentando que se trata de una creación legal del federalismo de concertación, que forma parte del derecho intrafederal y que una vez que la legislatura la ratifica queda incorporada al derecho público interno de cada provincia, resultando imposible su derogación unilateral por cualquier parte. Dicha Jurisprudencia de la Corte es mencionada por Abalos, 2015: 8, haciendo referencia a los fallos: CSJN, 20/08/1991 "Transporte Automotores Chevalier S.A. c/ Prov. Buenos Aires", Fallos t.314:862, también CSJN 19/08/1999 "Asociación de Grandes Consumidores de Energía Eléctrica de la República Argentina (AGUEERA) v. Provincia de Buenos Aires", Fallos t. 322:1781.

La ley vigente, de Coparticipacion federal de impuestos, se encuentra en deuda con nuestro federalismo, establece como único criterio de distribución el sistema de porcentajes fijos, resultando inconstitucional a la luz de la reforma constitucional de 1994, que prevé en el inciso 2 del artículo 75 criterios de reparto tanto para la distribución primaria como secundaria. El criterio que sigue la ley vigente 23. 548 , se basa en porcentajes fijos ,que han surgido de un acuerdo ocasional del Congreso ,responden a una situación normalmente estática, no prevén el paso del tiempo, no permiten el estímulo de acciones para revestir iniquidades. La ley 23.548 dictada en enero de 1988, establece, según el artículo 15, su prorroga automática en caso de no ser dictada una nueva ley convenio de Coparticipacion. El articulo 15 dice que: "la presente ley regirá desde el 1 de enero de 1988 hasta el 31 de diciembre de 1989. Su vigencia se prorrogará automáticamente ante la inexistencia de un régimen sustitutivo del presente."

${ }^{6}$ A esta normativa se la entiende como intrafederal, la misma surge con el fin de impedir la superposición de tributos en un país federal, logrando coordinar las facultades tributarias entre Nación, provincias y municipios. Algunas normas pretenden evitar la superposición vertical (entre Nación, provincias y municipios), a través de normas como la ley de Coparticipación Federal y el Pacto Fiscal Federal para el empleo, la producción y el crecimiento; en tanto que otras normas tratan de impedir la superposición horizontal, de provincias con provincias, y de municipios con municipios, tal es el caso del Convenio Multilateral del 18 de agosto de 1977. El Pacto Fiscal I, de 1992 Ratificado por ley 24. 130, establece la retención del $15 \%$ de la masa coparticipable para el financiamiento de la seguridad social nacional; prevé una garantía de Coparticipacion; se consagra la automaticidad en las transferencias de algunos fondos nacionales y un fondo compensador de déficits provinciales. En el año 1993, el Pacto Fiscal II, (ley 24. 307), también llamado Pacto Federal para el Empleo, la Producción y el Crecimiento. 1. No modifica la retención del $15 \%$, establecido en el Pacto Fiscal I. 2. Amplía la 
Goñi, M.J. Federalismo fiscal. Importancia de la autonomía municipal para el desarrollo sostenible. Derecho y Ciencias Sociales. Abril 2017. № 16 (Temas relativos al desarrollo regional y local) Pgs 22- 39. ISNN 1852-2971. Instituto de Cultura Jurídica y Maestría en Sociología Jurídica. FCJ y S. UNLP.

actualidad se ha tornado inequitativo ocasionando que los aportes del tesoro nacional, artículo 75, inciso $9,{ }^{7}$ de la Constitución Nacional dejaran de ser recursos extraordinarios para constituirse en ordinarios.

En la actualidad, las provincias se reservan la aplicación de impuestos tales como: ingresos brutos, automotores, al consumo de energía eléctrica, a los bienes inmuebles y sellos, los cuales no cubren la totalidad de los gastos provinciales. Con respecto a las provincias que perciben regalías por recursos naturales renovables, encuentran importes inferiores a lo que se les corresponde aplicar.

\section{2. El municipio en el Estado federal argentino, concepto, autonomía y competencias.}

garantía del monto fijo, llevándolo a $\$ 45,8$ millones.3. Obliga a las provincias a adoptar decisiones en materia de impuestos, como derogar los impuestos a los sellos, los que graven transferencias de combustibles, gas, energía eléctrica y servicios sanitarios; las tasas municipales que afecten hechos imponibles por las provincias; intereses de depósitos a plazo fijo y en caja de ahorros. Dicho pacto fiscal II, obliga también a modificar el impuesto a los ingresos brutos e inmobiliarios y sustituir primero en un plazo perentorio por otro impuesto general a los consumos que garantice neutralidad. Además exige propender a la privatización, concesión o liquidación de las empresas del Estado provincial y desregular los mercados particulares y transferir las cajas de jubilaciones Provinciales a la órbita nacional. La mencionada detracción del $15 \%^{6}$ ha sido un punto de conflicto para las provincias con el Estado nacional (pre coparticipación) para el financiamiento del sistema de Seguridad Social , donde el gobierno nacional transfiere una parte del financiamiento a las provincias influyendo el la distribución primaria de la coparticipación. El "acuerdo entre el Gobierno Nacional y los gobiernos provinciales" del 12 de agosto de 1992, fue ratificado por ley 24.130 y prorrogada sucesivamente por numerosos pactos intrafederales de la misma naturaleza; una vez vencidos los compromisos el Estado nacional extendió a partir del $1^{\circ}$ de enero de 2006 el plazo de esa deducción de manera unilateral mediante el artículo 76 de la ley 26. 078 que la Corte Suprema de la Nación declaró inconstitucional en la causa, donde la hizo lugar a las demandas planteadas por las provincias de Santa Fe y San Luis ("Santa Fe, Provincia de c/ Estado Nacional s/ acción declarativa de inconstitucionalidad” y CSJ 191/2009(45-S)/CS1 "San Luis, Provincia de c/ Estado Nacional s/ acción declarativa de inconstitucionalidad y cobro de pesos"). Con fundamento en esta decisión, la Corte ordenó al Estado Nacional, con carácter de medida cautelar, que suspenda de manera inmediata los descuentos que se le venían realizando a la Provincia de Córdoba sobre fondos de la coparticipación federal de impuestos (CSJ 786/2013 (49-C)/CS1 Córdoba, Provincia de c/ Estado Nacional y otro s/ medida cautelar).

${ }^{7}$ Los subsidios del tesoro, el artículo 75 Inc. 9 C. N. Son una atribución del Congreso consagrada en el inciso 9 del artículo 75, de acordar subsidios del Tesoro nacional a las provincias cuyas rentas no alcancen, según sus presupuestos, a cubrir sus gastos ordinarios. Cada provincia tiene sus ingresos que financian sus gastos públicos, previstos en el presupuesto local., pero en caso que los gastos ordinarios que surjan del presupuesto sean superiores a los ingresos, es atribución del Congreso federal otorgar subsidios. El régimen vigente de coparticipación Federal, dispone, en su artículo. $3^{\circ}$, la forma de distribución primaria de la masa coparticipable, en cuyo último Inc. d se expresa el porcentaje (1\% de la masa) será destinado al Fondo de Aportes del Tesoro Nacional, ATN, que se forma del conjunto de los recursos recaudados por el Gobierno Federal, cuyo monto se extiende a los que reciben las provincias. Por su parte, el artículo. $5^{\circ}$, de la ley de coparticipación federal dispone: en el ARTICULO $5^{\circ}$ que el "El Fondo de Aportes del Tesoro Nacional a las Provincias creado por el inciso d) del artículo 3 de la presente Ley se destinará a atender situaciones de emergencia y desequilibrios financieros de los gobiernos provinciales y será previsto presupuestariamente en jurisdicción del Ministerio del Interior, quien será el encargado de su asignación. El Ministerio del Interior informará trimestralmente a las provincias sobre la distribución de los fondos, indicando los criterios seguidos para la asignación. El Poder Ejecutivo Nacional no podrá girar suma alguna que supere el monto resultante de la aplicación del inciso d) del artículo $3^{\circ}$ en forma adicional a las distribuciones de fondos regidos por esta ley salvo las previstas por otros regímenes especiales o créditos específicos del presupuesto de gastos de administración de la Nación." 
Goñi, M.J. Federalismo fiscal. Importancia de la autonomía municipal para el desarrollo sostenible. Derecho y Ciencias Sociales. Abril 2017. № 16 (Temas relativos al desarrollo regional y local) Pgs 22- 39. ISNN 1852-2971. Instituto de Cultura Jurídica y Maestría en Sociología Jurídica. FCJ y S. UNLP.

El municipio, de acuerdo con Hernández, 1997: 246, es una “institución políticoadministrativa- territorial, basada en la vecindad, organizada jurídicamente dentro del Estado, para satisfacer las necesidades de vida de la comunidad local, en coordinación con otros entes territoriales y servicios estatales".

La Constitución Nacional reformada, en el año 1994, consagra la autonomía municipal, en el artículo 123 que dice: "Cada provincia dicta su propia constitución, conforme a lo dispuesto por el Artículo $5^{\circ}$ asegurando la autonomía municipal y reglando su alcance y contenido en el orden institucional, político, administrativo, económico y financiero.” El Art. 5º de la Constitución Nacional dice que: "Cada provincia dictará para sí una Constitución bajo el sistema representativo republicano, de acuerdo con los principios, declaraciones y garantías de la Constitución Nacional; y que asegure su administración de justicia, su régimen municipal, y la educación primaria. Bajo de estas condiciones el Gobierno federal, garante a cada provincia el goce y ejercicio de sus instituciones."

Para Hernández, 1997: 373, la autonomía es “... una cualidad especifica de la corporación, que la distingue de otras corporaciones: su capacidad de gobierno propia... su facultad de organizarse, en las condiciones de la ley fundamental, de darse sus instituciones y de gobernarse por ellas con prescindencia de todo otro poder". Se entiende que la autonomía constituye una noción de subordinación a un ente superior que, en el supuesto de no cumplimiento de ciertos requisitos o condiciones, lo autoriza a intervenir. La autonomía y la autarquía suponen descentralización, en el caso de la autonomía, la descentralización es política y en el caso de la autarquía la descentralización es administrativa. La autonomía puede ser plena o semiplena. La autonomía municipal es plena si comprende los cuatro aspectos que integran la autonomía (institucional, político, administrativo y financiero), y es semiplena o relativa (cuando únicamente alcanza a los aspectos político, administrativo y financiero).

En cuanto a las competencias municipales, los municipios son órganos de gobierno que en el marco del artículo 123 de la constitución Nacional, tienen facultades propias con respecto a las actividades cumplidas en su ámbito jurisdiccional o a las cosas situadas dentro de tales limites, sin exceder las materias de sus competencias.

\subsection{La autonomía económico financiera de los municipios, implicancias y alcances de sus contenidos.}

La autonomía económico financiera, es reconocida a los municipios en el artículo 123 de la Constitución Nacional, reformada en el año, 1994.La autonomía económica para Fazio, 2010: 338, supone la “...facultad del municipio de procurarse sus recursos propios sin intervención 
Goñi, M.J. Federalismo fiscal. Importancia de la autonomía municipal para el desarrollo sostenible. Derecho y Ciencias Sociales. Abril 2017. № 16 (Temas relativos al desarrollo regional y local) Pgs 22- 39. ISNN 1852-2971. Instituto de Cultura Jurídica y Maestría en Sociología Jurídica. FCJ y S. UNLP.

de ningún otro orden estatal sin perjuicio de que a algunos de ellos los perciba de otros niveles de gobierno en virtud de regímenes de coparticipación...” y la autonomía financiera consiste en la percepción e inversión de recursos. Para Hernández, 1997: 373, la autonomía económico financiera "comprende la libre creación, recaudación e inversión de las rentas para satisfacer sus fines, que no son otros que el bien común de la sociedad local.”

En cuanto al alcance de la autonomía municipal que surge del caso "Municipalidad de la Capital de la Provincia de La Rioja s/ Amparo", en el año 2014, en la causa Recurso de hecho Intendente Municipal Capital s/ Amparo. En atención al incumplimiento por parte de la Provincia de la Rioja de dictar el régimen de coparticipación municipal previsto su constitución y en el artículo 9 Inc. $\mathrm{G}$ de la ley 23. 548, de conformidad con los artículos 5 y 123 de la Constitución Nacional. El más alto tribunal se expresa acerca de la autonomía económico financiera destacando, entre otros los siguientes aspectos: 1. La autonomía económico financiera efectiviza la autonomía municipal. 2. Las provincias que no cumplan con los principios de la autonomía municipal serán susceptibles de intervención federal. 3. El fallo se refiere también al control y al manejo de los recursos municipales, independientemente de otro poder, completando las actividades de administración que le son propias. Al referirse a las competencias municipales en el considerando 9 dice que, la reforma mantuvo la potestad de que cada provincia al dictar su propia constitución debe hacerlo, en un marco de contenidos, que deben ser definidos y precisados por las provincias con el fin de coordinar los poderes que conservan artículos 121, 122, 124 y 125, con el mayor grado posible de atribuciones municipales en los ámbitos de actuación mencionados en el artículo 123.

\subsection{El poder tributario: concepto y alcances.}

Para Raúl Heredia, 2005: 166 el poder tributario significa la facultad o la posibilidad jurídica del Estado de exigir contribuciones con respecto a personas o bienes que se hallan en su jurisdicción; es la facultad de aplicar contribuciones o de establecer exenciones, o sea, el poder de sancionar normas jurídicas de las cuales derive o pueda derivar, a cargo de determinado individuo o de determinada categoría de individuos, la obligación de pagar un impuesto o de respetar un límite tributario, en concepto de Berliri adoptado por Giuliani Fonrouge, quien agrega: "Es, en suma, la potestad de gravar".

Con respecto a las potestades municipales originarias en materia de impuestos, la doctrina y la jurisprudencia se encontraron divididas. Algunos especialistas, en derecho tributario, sostuvieron que los municipios no pueden establecer impuestos, sino solamente tasas retributivas de servicios, salvo que el poder impositivo les haya delegado expresamente. Dicha 
Goñi, M.J. Federalismo fiscal. Importancia de la autonomía municipal para el desarrollo sostenible. Derecho y Ciencias Sociales. Abril 2017. № 16 (Temas relativos al desarrollo regional y local) Pgs 22- 39. ISNN 1852-2971. Instituto de Cultura Jurídica y Maestría en Sociología Jurídica. FCJ y S. UNLP.

postura que sustenta el poder tributario derivado de los municipios, se basa en la concepción de la autarquía de los mismos. Raúl Heredia: 2005, Dice que a pesar del aporte proveniente desde la doctrina municipalista persiste en la actualidad la clásica idea que el municipio es "un nivel inferior de gobierno." El autor mencionado, dice que actualmente se sostiene que el artículo 123 de la Constitución Nacional sigue permitiendo la vigencia de la interpretación basada en la autarquía municipal. Para la mayor parte de la doctrina tributarista, las provincias y la Nación tienen poder tributario originario ${ }^{8}$ debido a que se encuentra establecido expresamente en la Constitución Nacional y los municipios tienen poder tributario derivado o delegado porque no se encuentra directamente reconocido en la ley fundamental. Giuliani Fonrouge sostiene que, la Nación, las provincias y los municipios tienen poder tributario originario de la misma naturaleza.

Álvarez Echagüe, 2000: 16, sigue las expresiones vertidas por los miembros informantes de la Convención Constituyente en la que Hugo Prieto afirmó que “...los municipios argentinos van a poder generar sus rentas y recaudar para invertir y controlar sus propios recursos, a su vez, podrán ser manejados independientemente de otro poder." 9 y que la "...la autonomía municipal enmarcada en este nuevo esquema de poder en la Argentina a partir de la Reforma Constitucional va a contribuir a lograr una democracia más eficiente que propenda al bien común..."

De acuerdo a la constitución reformada, algunos autores sostienen que nada ha cambiado, así comenta Álvarez Echagüe , 2000: 14 que Cassagne, desde el Derecho Administrativo, dice que las constituciones provinciales deben determinar qué municipios se encuentran habilitados a dictar sus cartas orgánicas y cuáles no y para Bulit Goñi, ${ }^{10}$, desde el derecho tributario, nada ha cambiado con la reforma constitucional de 1994, los municipios continúan subordinados al

\footnotetext{
8 Álvarez Echagüe, 2000: 16, considera que el criterio mayoritario basa su argumentación en el texto de la Constitución Nacional y el otro criterio no hace distinción alguna partiendo de la necesidad que tienen los órganos de gobierno de contar con los recursos necesarios, a fin de cumplir con sus cometidos constitucionales. El autor citado avala la postura de Giuliani Fonrouge para quien no se puede concebir un gobierno que no cuente con poder tributario a fin de cumplir con sus obligaciones. Álvarez Echagüe, 2000: 16, afirma que las provincias cuentan con poder tributario originario, que surge del artículo 121 de la Constitución Nacional, por el cual conservan todo el poder no delegado al gobierno federal, resultando que la Nación y los municipios poseen poder tributario derivado proveniente de la delegación que las provincias hicieran en la Constitución Nacional, al momento de dictarla. Dice el tributarista mencionado que luego de la reforma constitucional de 1994, los municipios, según lo establecido en el artículo 123, y en el artículo 75 inciso 30 tienen reconocida de manera expresa en la constitución nacional poder tributario más allá del mayor o menor alcance que se le asigne, en el mismo sentido que la Corte Suprema de Justicia de la Nación en la causa "Telefónica de Argentina c. Municipalidad de Chascomús s. acción meramente declarativa".

${ }^{9}$ La negrita pertenece a Álvarez Echagüe 2000: 20.

${ }^{10}$ Bulit Goñi, citado por Álvarez Echagüe, 2000: 14 dice que hay en todo el territorio nacional aproximadamente 1.700 municipalidades resultando imposible lograr la coordinación de los mismas, que la reforma constitucional tuvo como objeto fortalecer el federalismo con una nación soberana, las provincias autónomas y los municipios autárquicos.
} 
Goñi, M.J. Federalismo fiscal. Importancia de la autonomía municipal para el desarrollo sostenible. Derecho y Ciencias Sociales. Abril 2017. № 16 (Temas relativos al desarrollo regional y local) Pgs 22- 39. ISNN 1852-2971. Instituto de Cultura Jurídica y Maestría en Sociología Jurídica. FCJ y S. UNLP.

ordenamiento provincial, ya que se permite mantener la vigencia de la ley de coparticipación, los pactos fiscales y el Convenio Multilateral.

\section{3. Recepción de la facultad de los municipios de percibir impuestos, en el Derecho Público Provincial y Municipal.}

Con respecto a las constituciones provinciales las mismas varían, el problema es que la redacción del artículo 123 otorga un margen de discrecionalidad a las provincias para establecer los alcances de la autonomía económico financiera allí reconocida.

Álvarez Echagüe, 2000: 27, entiende a diferencia de un sector de la doctrina que la potestad de reglar el alcance y contenido de la autonomía municipal existe de manera limitada, entendiendo conveniente que la provincia deslinde tales potestades en la constitución para evitar conflictos por el manejo de las legislaturas al reglamentarlo por ley. Dice que la provincia deberá deslindar los impuestos que serán, de su competencia exclusiva, y los que les corresponden a los municipios de su jurisdicción encontrando como limitación la de conferir los recursos tributarios que le permitan cumplir con sus funciones, con las transferidas y las que se les transmitan. Con respecto al alcance del Poder tributario al autor citado, piensa al igual que Villegas y Baistrocchi que a las comunas les es aplicable la teoría de la permisión, que las municipalidades pueden ejercer atribuciones tributarias con total libertad, estableciendo todo tipo de tributos, en tanto la provincia no lo limite teniendo en cuenta siempre las limitaciones provenientes de la Constitución Nacional y la legislación del Gobierno Federal.

En cuanto a las limitaciones que surgen de la Constitución Nacional a la potestad tributaria municipal, las mismas derivan de la delegación de competencias que efectúan las provincias y se proyectan sobre los tributos municipales. La potestad tributaria de los municipios encuentra en la Constitución Nacional limitaciones que surgen de normas que provienen de la parte dogmática de la Constitución, como asimismo de los tratados sobre derechos humanos con jerarquía constitucional que enumera el Inc. 22 del Art. 75: Así la competencia exclusiva de la Nación para gravar los derechos de importación y exportación excluye la posibilidad de que tales tributos sean utilizados por las provincias o por los municipios, Arts. 4 y 75, inciso 1; la denominada "cláusula comercial" a través de la cual las leyes que dicte el Congreso limitan el poder tributario, tanto provincial como municipal, art. 75 inc. 13; la cláusula del progreso, establecida en el inc.18 del art. 75, por medio de la cual el Congreso puede dictar normas que limiten el ejercicio de facultades provinciales y municipales; la relativa a los establecimientos de utilidad nacional, que por imperio del Poder Legislativo las provincias y municipios pueden ver desplazadas, sus potestades tributarias, cuando su ejercicio obstaculice con el 
Goñi, M.J. Federalismo fiscal. Importancia de la autonomía municipal para el desarrollo sostenible. Derecho y Ciencias Sociales. Abril 2017. № 16 (Temas relativos al desarrollo regional y local) Pgs 22- 39. ISNN 1852-2971. Instituto de Cultura Jurídica y Maestría en Sociología Jurídica. FCJ y S. UNLP.

cumplimiento de ese fin, aunque no en forma permanente sino en tanto dure tal utilidad, consagrada en el inc. 30 del art. 75; y la prohibición para las provincias y los municipios de establecer "aduanas interiores", arts. 9, 10 y 11.

Con respecto a las limitaciones que provienen de la parte dogmática surge que los derechos, principios y garantías derivados del texto constitucional y los tratados sobre derechos humanos con jerarquía constitucional (art. 75 inc. 22 Const. Nac.) limitan las potestades tributarias de los distintos ordenes de de gobierno, ${ }^{11}$ por ejemplo, las protegen el derecho de propiedad, y las que limitan la acción del poder público en relación al contribuyente tales como, los principios de legalidad, de igualdad, de generalidad, de no confiscatoriedad, de irretroactividad, de razonabilidad, de equidad, de proporcionalidad, etc.

Con respecto a las limitaciones al poder tributario de los municipios que surgen de la ley de coparticipación, el Art. 9, inc. b), de la ley de coparticipación $\mathrm{N}^{\circ} 23.548$, establece limitaciones con relación al alcance de su potestad tributaria.

"Art. 9: La adhesión de cada Provincia se efectuará mediante una ley que disponga: a. que acepta el régimen de esta ley sin limitaciones ni reservas; $b$. que se obliga a no aplicar por sí y a que los organismos administrativos y municipales de su jurisdicción, sean o no autárquicos, no apliquen gravámenes locales análogos a los nacionales distribuidos por esta ley. En cumplimiento de esta obligación no se gravarán por vía de impuestos, tasas, contribuciones $u$ otros tributos, cualquiera fuere su característica o denominación, las materias imponibles sujetas a impuestos nacionales distribuidos, ni las materias primas utilizadas en la elaboración de productos sujetos a los tributos a que se refiere esta ley. Esta obligación no alcanza a las tasas retributivas de servicios efectivamente prestados..."

Además el poder tributario de los municipios se encuentra limitado por el convenio multilateral del 18 de agosto de 1977, siendo su finalidad evitar la doble o múltiple imposición originada por la aplicación del Impuesto sobre los Ingresos Brutos a contribuyentes que desarrollen actividades interjurisdiccionales. Dicho convenio es un instrumento de coordinación de las

\footnotetext{
${ }^{11}$ El "Estatuto constitucional de derechos y garantías del contribuyente, limita el ejercicio del poder tributario en el orden local, resultando aplicable a todas las jurisdicciones, de acuerdo con el Art. 5 de la Constitución Nacional, norma que garantiza el libre goce y ejercicio de las instituciones provinciales a condición de que las provincias dicten para si una constitución conforme a los principios, declaraciones y garantías de la Ley Fundamental. Este Estatuto se sustenta del "Derecho Constitucional de la Libertad", en el cual confluyen los contenidos de la Parte Dogmática de la Constitución Nacional, junto con otros derechos y garantías que surgen de los tratados internacionales sobre derechos humanos que se integran a la Constitución en las condiciones del artículo 75, inciso 22.
} 
Goñi, M.J. Federalismo fiscal. Importancia de la autonomía municipal para el desarrollo sostenible. Derecho y Ciencias Sociales. Abril 2017. № 16 (Temas relativos al desarrollo regional y local) Pgs 22- 39. ISNN 1852-2971. Instituto de Cultura Jurídica y Maestría en Sociología Jurídica. FCJ y S. UNLP.

facultades tributarias a nivel horizontal, que ha sido acordado entre las Haciendas provinciales. El Art. 35 del mencionado convenio, establece que es aplicable, en el ámbito municipal, a los que establezcan cualquier tipo de tributos sobre los comercios, industrias o actividades ejercidas en el respectivo ámbito jurisdiccional, y que tome como base de imposición a los ingresos obtenidos por los entes económicos en el desarrollo de su actividad.

En el Derecho Público Provincial, algunas constituciones se refieren de manera genérica la posibilidad de que los municipios apliquen impuestos tales como las de Córdoba, Art. 188, Buenos Aires Arts 192, Inc. 5 y 193 Inc. $2^{12}$, Entre Ríos Art. 188 y La Pampa Art. 121, y para el caso de la Provincia de Santa Fe el tema queda librado a la Ley Orgánica de las municipalidades. ${ }^{13}$ Un caso particular que afirma las atribuciones originarias de los municipios es la constitución de la Provincia de San Juan en el Art. 253. "El tesoro del municipio estará formado por: 1) Los impuestos cuya percepción no haya sido delegada a la provincia," Otras constituciones mencionan expresamente que tipo de impuestos pueden percibir los municipios. ${ }^{14}$ Algunas constituciones como las de: Córdoba, Corrientes, Entre Ríos, Santa Cruz, Santiago del Estero y Tierra del Fuego, entre otras hacen referencia a los límites a la capacidad impositiva municipal que surgen de la Constitución Nacional. Las constituciones de Córdoba, Art 188 y Tierra del Fuego Art 179 se refieren a los principios constitucionales de la

12 Santa Fe ARTICULO 107. Los municipios son organizados por la ley...3) con las atribuciones necesarias para
una eficaz gestión de los intereses locales, a cuyo efecto la ley los proveerá de recursos financieros suficientes. A
este último fin, pueden crear, recaudar y disponer libremente de recursos propios provenientes de las tasas y demás
contribuciones que establezcan en su jurisdicción. ...”. Mendoza Art. $197^{\circ}$ - La administración de los intereses y
servicios locales en la capital y cada uno de los departamentos de la Provincia, estará a cargo de una
municipalidad, compuesta de un Departamento Ejecutivo y otro Deliberativo, cuyos miembros durarán 4 años en
el ejercicio de sus funciones, renovándose el Departamento Deliberativo por mitades cada 2 años. Inc. 6 - Las
municipalidades tendrán las rentas que determine la Ley Orgánica y en ningún caso podrán dictar ordenanzas
creando impuestos ni contribuciones de ninguna clase, salvo respecto de los servicios municipales. ${ }^{13}$ Catamarca, Art. 253. - El Tesoro Municipal se formará: ...Con los impuestos permanentes o transitorios que se crearen especialmente sobre las industrias y profesiones ejercidas en su jurisdicción; sobre diversiones y espectáculos públicos, sobre publicidad, cualquiera fuere el medio empleado, patente de automotores, licencia de conductores, introducción de productos alimenticios, ocupación de la vía pública y lo que fijó la Carta Orgánica Municipal o la Ley Orgánica de municipalidades y Comunas..." Chaco, Recursos municipales Artículo 197: "Son recursos municipales: 1) El impuesto inmobiliario sobre bienes raíces ubicados en el municipio y al mayor valor de la tierra libre de mejoras..." Corrientes Art. 164.- "Son recursos municipales: 1) La participación en el impuesto inmobiliario que se percibe en su jurisdicción, en la proporción que determine la ley hasta un 50\% de dicho impuesto." Formosa Art.178.- Son recursos propios del municipio: "1. El impuesto inmobiliario y gravámenes sobre tierras libres de mejoras." Misiones Art. 167.- "Son recursos municipales, sin perjuicio de los demás que la ley establezca: 1) el impuesto a la propiedad inmobiliaria y a las actividades lucrativas, en concurrencia con la Provincia y en la forma que la ley determine..." Neuquén Art. 205 -"Son recursos propio

${ }^{14}$ Córdoba, Art. 188.- "Las Municipalidades disponen de los siguientes recursos: 1. Impuestos municipales establecidos en la jurisdicción respectiva, que respeten los principios constitucionales de la tributación y la armonización con el régimen impositivo provincial y federal.” Tierra del Fuego Art 179.- El tesoro municipal está compuesto por:"...2. Lo recaudado en concepto de impuestos, tasas, derechos, patentes, contribuciones de mejoras, multas y tributos necesarios para el cumplimiento de los fines y actividades propias, que respeten los principios constitucionales de la tributación y la armonización con el régimen impositivo provincial y federal, prohibiéndose la doble imposición.” 
Goñi, M.J. Federalismo fiscal. Importancia de la autonomía municipal para el desarrollo sostenible. Derecho y Ciencias Sociales. Abril 2017. № 16 (Temas relativos al desarrollo regional y local) Pgs 22- 39. ISNN 1852-2971. Instituto de Cultura Jurídica y Maestría en Sociología Jurídica. FCJ y S. UNLP.

tributación. ${ }^{15}$ En el caso de Chubut, Art. 239.- "Los municipios tienen rentas y bienes propios, siendo exclusiva su facultad de imposición respecto de las personas cosas o formas de actividad sujetas a jurisdicción municipal..."

\section{1. Coparticipación de las provincias hacia los municipios: Concepto.}

La coparticipación de la provincia hacia los municipios, es una fuente de financiamiento normal y trascendente para los gobiernos municipales, es la parte fundamental de los ingresos municipales ordinarios de otra jurisdicción, se trata de recursos que las provincias coparticipan a las jurisdicciones locales en concepto de impuestos provinciales y nacionales. La Coparticipación municipal se fundamenta en las constituciones provinciales y en la legislación específica. Todas las provincias dictan sus leyes de coparticipación presentando una variada regulación sobre el tema, consagrando porcentajes fijos de distribución primaria y enunciados de distribución secundaria, en base a criterios establecidos ya sea en las en las constituciones y legalmente o solamente en la ley. Las provincias de San Juan ${ }^{16}$, La Rioja ${ }^{17}$ y Jujuy ${ }^{18}$ dice Montbrun, 2003: 451 que presentan regímenes transitorios y de emergencia.

En la Coparticipación municipal, la distribución primaria, que parte de la provincia hacia sus municipios se compone por recursos nacionales y provinciales que son coparticipados por la provincia a la totalidad de sus municipios. Algunas constituciones provinciales fijan porcentajes mínimos de coparticipación primaria, con el fin de paliar los márgenes de discusión y discrecionalidad. A la Coparticipación primaria, de las provincias a los municipios, le son aplicables los indicadores a los que ya nos referimos al explicar la coparticipación federal. La distribución secundaria consiste en la ejecución de un nuevo reparto que surge del porcentaje que se les atribuye a los distintos municipios de la provincia, como resultado de la coparticipación primaria. Con respecto a este tema, surgen del Derecho Público Provincial,

\footnotetext{
${ }^{16}$ De acuerdo con Garriga y Rosales, 2015: 304, rigen convenios celebrados cada año entre la provincia y sus municipios, consistentes en la transferencia de porcentajes fijos para el pago de la remuneración de los empleados municipales.

17 En el año 2014, en la causa "Recurso de hecho", deducido por la Municipalidad de La Rioja, en la causa "Intendente Municipal Capital s/ amparo" (noviembre de 2014) se hizo lugar al pedido de inconstitucionalidad del incumplimiento por la provincia de dictar la ley de coparticipación municipal, obligándola a hacerlo. En Corte Suprema de Justicia de la Nación, en el caso, RECURSO DE HECHO Intendente Municipal Capital si amparo.

${ }^{18}$ El régimen transitorio de coparticipación municipal se fundamenta en leyes de emergencia económica, para asistir a los municipios en el pago de los empleados municipales y en el financiamiento y amortización de deuda y de obras públicas.
} 
Goñi, M.J. Federalismo fiscal. Importancia de la autonomía municipal para el desarrollo sostenible. Derecho y Ciencias Sociales. Abril 2017. № 16 (Temas relativos al desarrollo regional y local) Pgs 22- 39. ISNN 1852-2971. Instituto de Cultura Jurídica y Maestría en Sociología Jurídica. FCJ y S. UNLP.

diversos prorrateadores que presentan ventajas e inconvenientes. Varias provincias establecen en sus constituciones, criterios para la distribución secundaria.

\section{2. Recepción en el Derecho Público Provincial.}

Algunas constituciones provinciales fijan porcentajes mínimos de coparticipación primaria, con el fin de paliar los márgenes de discusión y discrecionalidad. Las Constitución de Córdoba, en su Art. 188 Inc. 3 establece como recursos municipales, los provenientes de la coparticipación provincial y federal, cuyos porcentajes no pueden ser inferiores al veinte por ciento; la Constitución de Santa Fe, en su Art., 107 dice que los municipios tienen asimismo participación en gravámenes directos o indirectos que recaude la provincia, con un mínimo del cincuenta por ciento del producido del impuesto inmobiliario; la Constitución de Santiago del Estero, señala en su Art. 220, Inc. 10, que las municipalidades dispondrán de los recursos provinciales que se perciban en su jurisdicción, en la siguiente proporción: a) no menos del veinticinco por ciento como participación de los impuestos provinciales; b) no menos del quince por ciento sobre la coparticipación de la provincia en los impuestos nacionales y de todo otro recurso cualquiera sea su denominación; la Constitución de Jujuy ${ }^{19}$, en su Art. 192, Inc. 6, establece que el tesoro municipal se integra también con recursos provenientes de : la participación en un cincuenta por ciento del impuesto inmobiliario, cuya distribución será determinada por la ley. Otras constituciones no consagran el tema. La provincia de Santiago del Estero prevé criterios de distribución primaria, Art. 213), y dice, siguiendo el mismo criterio que la Constitución Nacional que "La distribución de la coparticipación impositiva desde la provincia hacia los municipios, se efectuará en relación directa a las competencias, servicios y funciones de cada una de ellas...".

La distribución secundaria consiste en la redistribución de la coparticipación primaria entre los distintos municipios de la provincia. Con respecto a este tema, coexisten en el derecho provincial comparado diversos prorrateadores que presentan ventajas e inconvenientes que deben ser evaluados para resolver su utilización. En la coparticipación municipal, los criterios de distribución secundaria de recursos coparticipables, varían adoptando algunas provincias un criterio devolutivo con el objetivo de devolver a sus municipios una fracción de lo que se recauda en su territorio y en otras provincias se consagran criterios de distribución

\footnotetext{
19 De acuerdo con Garriga y Rosales, 2015: 305. en la Provincia de Jujuy se encuentra vigente un régimen transitorio de coparticipación municipal, por razones de emergencia económica, ocupándose la Provincia en asistir en el pago de las remuneraciones de empleados públicos, amortización de deuda y obras públicas.
} 
Goñi, M.J. Federalismo fiscal. Importancia de la autonomía municipal para el desarrollo sostenible. Derecho y Ciencias Sociales. Abril 2017. № 16 (Temas relativos al desarrollo regional y local) Pgs 22- 39. ISNN 1852-2971. Instituto de Cultura Jurídica y Maestría en Sociología Jurídica. FCJ y S. UNLP.

redistributivos con el fin de compensar a los municipios con menores caudales fiscales o mayor necesidad fiscal. Los indicadores utilizados son: inversa a la población, porcentaje de población con necesidades básicas insatisfechas, coeficientes de equilibrio de desarrollo regional, etc.

Con respecto a la coparticipación de la provincia a los municipios, la Corte Suprema de Justicia en el "Recurso de Hecho deducido por la Municipalidad de La Rioja en la Causa Intendente Municipal Capital s/ amparo", noviembre de 2014, resolvió hacer lugar al pedido de inconstitucionalidad del incumplimiento de la Provincia de dictar una ley de coparticipación municipal, de conformidad a lo ya establecido por la Constitución provincial, la Corte falló obligando a la provincia a hacerlo. El fallo vincula la coparticipación federal a la autonomía municipal $^{20}$.

\section{Conclusiones.}

La descentralización fiscal es difícil y compleja debido a que las disposiciones sobre recursos municipales previstas en las constituciones provinciales, no pueden desatender el marco del federalismo en el que se encuentran inmersas.

Para visualizar fuentes de recursos para los municipios debería contemplarse la potestad tributaria municipal en el ámbito de sus competencias. Dichas potestades pueden coordinarse y concertarse entre niveles de gobierno, a fin de evitar la superposición y sobrecarga impositiva sobre los contribuyentes. De acuerdo con Llach "Un federalismo bien estructurado puede resolver el dilema fundamental de todo sistema económico al crear un Estado suficientemente fuerte como para proteger los derechos de propiedad y demasiado débil para confiscar la riqueza de sus ciudadanos."

\footnotetext{
20 “.... $\left.3^{\circ}\right) \ldots$ el sistema de coparticipación de impuestos ha sido transgredido por la provincia y que de este modo se ha vulnerado además el artículo 75 Inc. 2 de la Constitución Nacional y la ley 23.548 de Coparticipación Federal. Relata que La Rioja a es la única provincia que no ha sancionado una ley de coparticipación de municipios; que, a partir del 3 de mayo de 2007, esta situación se agravó con el dictado de la ley 8149 que dispuso la suspensión de las leyes hasta entonces vigentes 8034 y 8067, que habían establecido la distribución de los gastos de funcionamiento de los 18 municipios de la provincia "hasta la sanción de una Ley de Coparticipación Municipal"(artículo $5^{\circ}$ de la ley 8034). Como consecuencia de ello, explica que en la actualidad solo criterios discrecionales gobiernan la distribución de fondos a los municipios, y que la municipalidad de la capital ha sido particularmente discriminada en el reparto; sostiene que ello compromete la prestación de los servicios públicos municipales." " $5^{\circ}$ ) Que al cerrar el debate de modo definitivo y por razones de "admisibilidad sustancial", el a quo omitió valorar que la Constitución Nacional establece en el artículo 123 un marco para la realización de un sistema federal que incluye un nivel de gobierno municipal autónomo cuyo alcance y contenido en el orden institucional, político , administrativo, económico y financiero debe ser reglado por cada constitución provincial: el actor sostiene que el Poder Legislativo de la provincia incumple esta obligación a pesar de que la manda constitucional ya está establecida en La Rioja."'
} 
Goñi, M.J. Federalismo fiscal. Importancia de la autonomía municipal para el desarrollo sostenible. Derecho y Ciencias Sociales. Abril 2017. № 16 (Temas relativos al desarrollo regional y local) Pgs 22- 39. ISNN 1852-2971. Instituto de Cultura Jurídica y Maestría en Sociología Jurídica. FCJ y S. UNLP.

Con respecto a la descentralización fiscal, la misma, puede hacerse en el marco de un reparto de competencias claras que se encuentren fundadas constitucionalmente para los cuatro niveles de gobierno. La descentralización debe contemplar la previsión del art 75 inc 2, III er párrafo que dice "La distribución entre la Nación, las provincias y la Ciudad de Buenos Aires y entre estas, se efectuara en relación directa a las competencias servicios y funciones de cada una de ellas contemplando criterios objetivos de reparto; será equitativa, solidaria y dará prioridad a un grado equivalente de desarrollo, calidad de vida e igualdad de oportunidades en todo el territorio nacional".

Entendemos al municipio como actor esencial en toda estrategia de desarrollo humano, para realizar el proyecto constitucional de "Proveer lo conducente al desarrollo humano, al progreso económico con justicia social, al crecimiento armónico de la Nación y al poblamiento de su territorio; promover políticas diferenciadas que tiendan a equilibrar el desigual desarrollo relativo de las provincias y regiones. Resulta necesario en este marco apuntalar la consagración de la autonomía institucional, política, administrativa, económica-financiera y participativa y confirmar la necesaria competencia del municipio para fortalecer nuestra democracia, como el ámbito más legítimo y favorable para el desarrollo de la vida política. Se estima necesario pensar la responsabilidad y correspondencia fiscal ${ }^{21}$ en el régimen federal. De manera que los gobiernos subnacionales puedan aumentar o reducir sus ingresos por medios que los hagan públicamente responsables de sus acciones.

En nuestro país, la dependencia vino de la mano de la centralización del gasto, que se ha acentuado en los últimos años y el desbalance vertical entre impuestos recolectados y gastos propios de cada nivel de gobierno. La responsabilidad fiscal se potencia si se ejerce el control ciudadano de manera más directa e inmediata. De acuerdo con el modelo de descentralización fiscal, no pueden impedirse las diferencias entre regiones ricas y pobres subsistiendo por equidad las transferencias intergubernamentales que deben tender a desaparecer en las regiones más ricas, debiendo tener como finalidad la atención de los desequilibrios para auxiliar las autonomías. Es necesario para esto superar la centralización impositiva que solo podrá lograrse si se convoca a los municipios en paridad como sujetos de nuestro Estado federal, en el marco de las competencias propias de cada orden de gobierno, Nacional, provincial y municipal.

\footnotetext{
21 Por correspondencia fiscal se entiende que “... se manifiesta cuando los ciudadanos electores (constituyen) perciben claramente, y en sus bolsillos, el costo oportunidad de las decisiones de gasto público marginal de 'su' gobierno susbancional." "...en los regímenes federales no solo ocurre que el mandato del gasto es difuso y de casi imposible convalidación. Al propio tiempo aparece una separación adicional entre quienes toman las decisiones y quienes toman las decisiones de recaudar."
} 
Goñi, M.J. Federalismo fiscal. Importancia de la autonomía municipal para el desarrollo sostenible. Derecho y Ciencias Sociales. Abril 2017. № 16 (Temas relativos al desarrollo regional y local) Pgs 22- 39. ISNN 1852-2971. Instituto de Cultura Jurídica y Maestría en Sociología Jurídica. FCJ y S. UNLP.

\section{Bibliografía.}

Abalos, M. (2015). Facultades impositivas municipales en el contexto federal. Cita online: La ley.

Ábalos, M. (2003). El régimen municipal en el derecho público provincial argentino: principales aspectos En Derecho Público Provincial y Municipal. Buenos Aires: La Ley.

Álvarez Echagüe, (2000). La autonomía de los municipios y sus derivaciones en el ámbito tributario”. Colegio de Abogados del Departamento Judicial de Bahía Blanca, Año III:

Ed Costa Sud,

Bertazza y otros (2015). Bases y lineamientos generales para una futura reforma tributaria. Consejo Profesional de Ciencias económicas de la Ciudad Autónoma de Buenos Aires: Edicon.

Garriga M y Rosales W (2015). Finanzas Públicas en la Práctica, selección de casos y aplicaciones. La Plata, Provincia de Buenos Aires: Ediciones Haber.

Hernández, Antonio María y otros, (2008). Derecho Publico Provincial, Buenos Aires: Ed Lexis Nexis.

Hernández, Antonio María (h), (1997). Derecho Municipal, Vol I, Teoría general, Buenos Aires: Ed Depalma.

Heredia, José Raúl, (2005) "El poder tributario de los municipios”, Buenos Aires: Ed Rubinzal Culzoni.

Instituto de estudios fiscales y económicos, (1996). "Las potestades tributarias de los municipios de la Provincia de Buenos Aires”, La Plata, 1996.

Montbrun, Alberto, en Pérez Guilhou y Otros, (2003). Recursos Provinciales. En "erecho Publico Provincial y Municipal, Avellaneda, Provincia de Buenos Aires: Editorial La Ley.

Porto, Alberto: (2012). Temas de economía de los gobiernos municipales, Buenos Aires: Ed. Dunken.

Reca Ricardo Pablo, (2013) Reflexiones sobre el régimen municipal Bonaerense, La Plata, Provincia de Buenos Aires: Ed Librería Editora Platense.

Fazio (2010) Régimen económico- financiero municipal, En Zarza Mensaque, Alberto y otros Introducción al Derecho Municipal, Córdoba: Ed Advocatus,

Ziulu, A, (1997) Derecho Constitucional, Buenos Aires: Ed. Depalma,

\section{Legislación.}

Constitución Nacional, consultada en www.infoleg.gov.ar Disponible en http://infoleg.mecon.gov.ar/infolegInternet/anexos/0-4999/804/norma.htm. 02/03/2016. 
Goñi, M.J. Federalismo fiscal. Importancia de la autonomía municipal para el desarrollo sostenible. Derecho y Ciencias Sociales. Abril 2017. № 16 (Temas relativos al desarrollo regional y local) Pgs 22- 39. ISNN 1852-2971. Instituto de Cultura Jurídica y Maestría en Sociología Jurídica. FCJ y S. UNLP.

Constituciones provinciales, fuente consultada: Constituciones provinciales http://www.infoleg.gob.ar/

Pacto fiscal I, consultado en http://infoleg.mecon.gov.ar/infolegInternet/anexos/04999/17/norma.htm. 07/03/2016

Pacto fiscal II, Consultado en http://infoleg.mecon.gov.ar/infolegInternet/anexos/50009999/9520/norma.htm. 02/03/2016 y http://servicios.infoleg.gob.ar/infolegInternet/anexos/5000-9999/9520/norma.htm. 16/12/2016.

\section{Jurisprudencia.}

Corte Suprema de Justicia de la Nación, en el caso, RECURSO DE HECHO Intendente Municipal Capital si amparo. Consultado en http://servicios.csjn.gov.ar/confal/ConsultaCompletaFallos.do?method=verDocumentos\&id=71 6748. $07 / 03 / 2016$

CSJ 538/2009 (45-S)/CSl ORIGINARIO Santa Fe, Provincia de cl Estado Nacional s /acción declarativa de inconstitucionalidad. Consultado en http://www.federalismofiscal.com/2015/11/corte-es-inconstitucional-retencion-del-15-paraanses/

CSJ 191/2009 (45-S)/CS1 ORIGINARIO San Luis, Provincia de c/ Estado Nacional s/ acción declarativa de inconstitucionalidad y cobro de pesos. Consultado en http://www.federalismofiscal.com/2015/11/corte-es-inconstitucional-retencion-del-15-paraanses/

CSJ 786/2013 (49-C)/ CSI ORIGINARIO Córdoba, Provincia de el Estado Nacional y otro si medida cautelar en Consultado en http://www.federalismofiscal.com/2015/11/corte-esinconstitucional-retencion-del-15-para-anses/ 